\title{
Sofrimento na Vigilância Prisional: O Trabalho e a Atenção em Saúde Mental
}

Suffering in arrest monitoring: The work and the mental health care

Cassiano Ricardo Rumin

Faculdades

Adamantinenses

Integradas/União das

Faculdades Dracenense
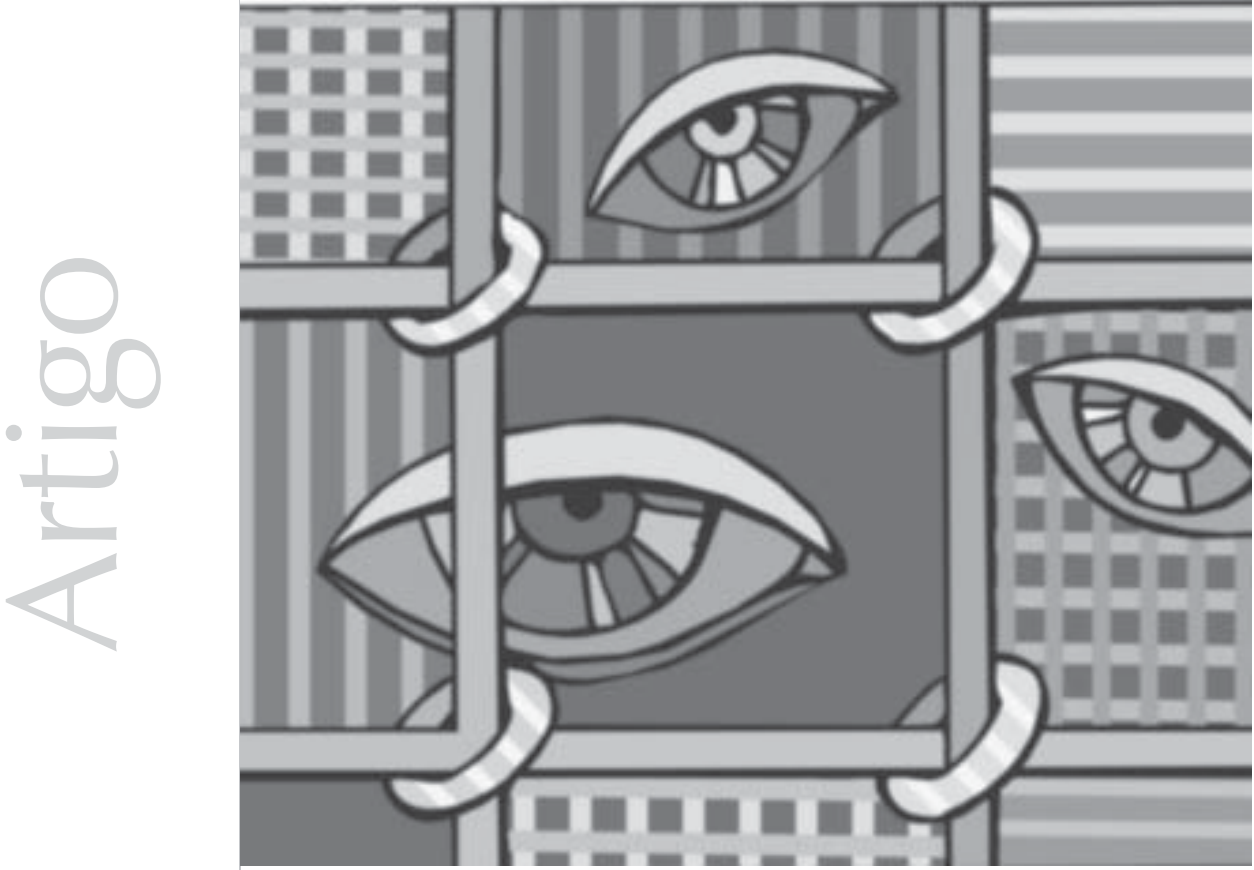


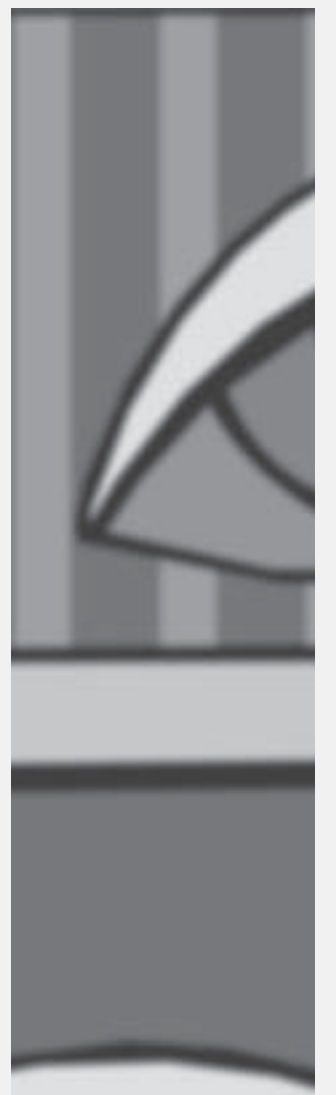

Resumo: Neste trabalho, apresentaremos uma caracterização das condições de trabalho dos agentes de segurança penitenciária (ASPs) e uma intervenção que culminou com a constituição de um espaço para o acolhimento do sofrimento psíquico dos trabalhadores. Realizamos trinta entrevistas semidirigidas individuais com ASPs de uma unidade prisional de regime fechado. O discurso dos ASPs apontou as seguintes situações ansiogênicas: risco constante de exposição à violência física no cotidiano prisional, temor em relação à segurança de seus familiares, exposição a doenças como tuberculose, hepatite C e HIV, percepção da degradação da saúde mental, trabalho monótono e sensação de enclausuramento em algumas funções, representação social pejorativa desse trabalho pela comunidade, baixa remuneração e restrição dos serviços de saúde oferecidos aos ASPs e seus dependentes. Após o reconhecimento dos determinantes de agravo à saúde, organizamos um espaço de escuta aos trabalhadores com a participação de graduandos que realizavam estágio profissionalizante em Psicologia. Esse espaço evoluiu da mobilização subjetiva para o enfrentamento das dinâmicas disciplinares institucionais às dinâmicas afetivas dos trabalhadores e ofereceu acolhida ao seu sofrimento, tendo sido organizado numa modalidade de atenção emergencial em saúde mental e em encontros individuais com os trabalhadores.

Palavras-chave: trabalho, saúde mental, penitenciárias.

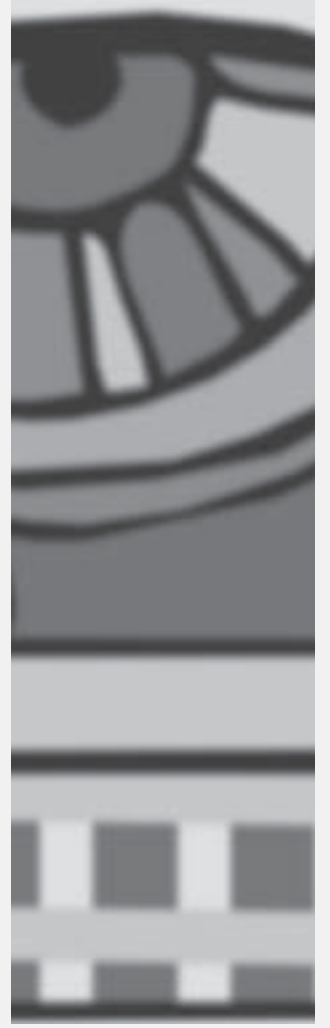

Abstract: In this work it will be presented a characterization of the prison security agents (PSAs) work conditions and an intervention that culminated in the constitution of a space for the psychic suffering workers' assistance. Thirty semidirected interviews with APSs from a closed regimen prison had been carried through. The PSAs speech had pointed the following distress generating situations: constant risk of physical violence exposition in the daily routine, concern about their relatives' safety, the exposition to illnesses as tuberculosis, hepatitis C and HIV, perception of mental health degradation, monotonous work and cloister like sensation in some functions, negative social impressions of their work by the community, low remuneration and restriction of the health services offered to the PSAs and their dependants. After the recognition of the determinative health aggravating factors, a space for the attendance was organized, with the participation of students who carried through a professionalizing period of training in Psychology. This space evolved from a subjective mobilization to a confrontation with the institutional discipline dynamics in relation to the workers' affection dynamics. It offered assistance to the suffering of the workers and it was organized in a modality of emergency care in mental health and individual meeting with the workmen.

Key words: work, mental health, prisons. 
A desativação do Complexo Penitenciário do Carandiru (SP), a expansão do sistema de carceragem do Estado de São Paulo e o interesse de prefeitos do interior deste Estado pela construção de presídios em seus limites administrativos determinaram a concentração de unidades penitenciárias com diversos modelos disciplinares no interior paulista.

De acordo com informações da Secretaria de Administração Penitenciária (2005), a partir de 1998, mais de 16000 vagas para abrigar sentenciados foram criadas no interior do Estado. Até o ano 2003, mais de 82000 detentos estavam reclusos nas unidades prisionais da SAP em 108 unidades prisionais: 76 penitenciárias, 18 centros de detenção provisória e 14 centros de ressocialização. Ainda se encontravam em processo de estudo, licitação ou construção mais sete centros de ressocialização, nove centros de detenção provisória, oito penitenciárias e duas alas de progressão penitenciária.

No oeste paulista, a reestruturação produtiva no setor bancário (Merlo, 2002), a desestruturação das atividades agrícolas (Camargo et al., 1995) e a ausência de estrutura industrial que pudesse ofertar postos de trabalho contribuíram intensamente para que as prefeituras locais buscassem a construção das unidades de detenção como alternativa de emprego e renda. Assim, o fato de a população local poder trabalhar nas penitenciárias porta, desde seu início, significados de expropriação (Moraes, 1999; 2004) das antigas relações de trabalho formal e das relações históricas constitutivas das famílias agricultoras da região.

\section{Objetivo}

Nesta apresentação, contribuímos com a caracterização das condições de trabalho e dos possíveis impactos sobre a saúde dos trabalhadores ocupados nos serviços de vigilância prisional. Verificamos ainda o desdobramento das dimensões institucionais sobre o espaço e as relações sociais fora do trabalho.

A partir do reconhecimento das condições de trabalho e do sofrimento psíquico resultante da prática profissional, propusemos o estabelecimento de um espaço de acolhimento ao sofrimento psíquico dos trabalhadores e de mobilização subjetiva para o enfrentamento das práticas institucionais, que foi constituído como um serviço de saúde mental inserido numa unidade prisional.

\section{Metodologia}

A metodologia utilizada para a caracterização das condições de trabalho foi a entrevista semidirigida. O roteiro de entrevista empregado na caracterização do trabalho contava com grupos temáticos que envolviam: a) os caracteres sociodemográficos do trabalhador; b) o histórico pessoal do trabalho; c) a descrição da organização e das condições de trabalho; d) a percepção da degradação da saúde do entrevistado e/ou do coletivo de trabalhadores; e) a representação social do trabalho para o entrevistado. Optamos por esse método de investigação pois, além de interessarmo-nos pelas formas de organização e as condições de trabalho (Dejours, 1994), poderíamos ter acesso ao discurso subjetivo do trabalho (Dejours, 2001), e, assim, avaliarmos a ocorrência do sofrimento psíquico relacionado à prática profissional e à pertinência da oferta de um modelo de atenção em saúde mental.

\section{Resultados}

A organização do trabalho

O horário de funcionamento do presídio é ininterrupto. Os horários de trabalho dos funcionários variam, pois são classificados em plantonistas e diaristas. Os plantonistas 
trabalham em regime de quatro turnos alternados, em escala de doze horas de atividade laboral, seguidas de trinta e seis horas de descanso. Já os diaristas trabalham de segunda-feira a sexta-feira, em escala de oito horas diárias.

Existem também alguns profissionais que trabalham em escala de horários mais flexíveis, cumprindo uma jornada semanal de vinte horas. São enfermeiros, médicos, farmacêuticos, dentistas e educadores. Os agentes de escolta e vigilância penitenciária podem ter sua jornada alterada em razão do deslocamento de sentenciados entre as unidades da Secretaria de Administração Penitenciária (SAP). O núcleo interdisciplinar é formado por psicólogos e assistentes sociais, que trabalham seis horas diárias nos dias úteis. Os funcionários são selecionados por meio de concurso público. O quadro de funcionários da penitenciária estudada será apresentado na tabela 1:

Tabela 1. Número de trabalhadores na penitenciária investigada, 2005

\begin{tabular}{|l|l|l|l|}
\hline Profissionais & postos de trabalho & \multicolumn{3}{c|}{ defasagem } \\
\hline & & N & $\%$ \\
\hline Psicólogo & 4 & 2 & 50 \\
\hline Assistente Social & 4 & 1 & 25 \\
\hline Médicos & 3 & 1 & 33 \\
\hline Dentistas & 2 & 1 & 50 \\
\hline Mecânico & 1 & - & - \\
\hline Atendente técnico de direção & 1 & - & - \\
\hline Oficial administrativo & 25 & 13 & 52 \\
\hline Motorista & 5 & 2 & 40 \\
\hline Eletricista & 2 & - & - \\
\hline Cozinheiro & 3 & - & - \\
\hline Marceneiro & 1 & - & - \\
\hline Serralheiro & 1 & - & - \\
\hline Enfermeira (o) & 3 & 1 & 33 \\
\hline Auxiliar de enfermagem & 5 & 1 & 20 \\
\hline Agente penitenciário & 200 & 20 & 10 \\
\hline Agente de escolta e vigilância & 42 & 8 & 19 \\
\hline Auxiliar de laboratório & 1 & - & - \\
\hline
\end{tabular}

Fonte: Unidade Penitenciária Estudada - Setor de Cadastro

Ao analisar as informações apresentadas na tabela 1, verificamos que a defasagem no número previsto de funcionários só não atinge os profissionais envolvidos com a manutenção das instalações e equipamentos da unidade prisional, tais como eletricista, marceneiro, serralheiro, mecânico. Nas demais atividades institucionais, a defasagem de funcionários varia entre aproximadamente $10 \%$ e $50 \%$. Essa defasagem de funcionários ocasiona uma sobrecarga de atividades aos trabalhadores e prejudica a qualidade dos serviços prestados.

Verificamos que o núcleo interdisciplinar (psicólogos e assistentes sociais) e os profissionais de saúde são as funções laborativas que contam com maior defasagem. Assim, atividades de atenção psicossocial, bem como o acolhimento do processo de saúde e doença, são negligenciadas pela estrutura organizacional do trabalho. Aos trabalhadores dessas funções, resta a quantidade aumentada de trabalho realizado, a exposição a queixas sobre o número reduzido de atendimentos oferecidos e deparam-se com situações divergentes em relação às determinações expressas em 


\section{A reestruturação produtiva determinou a redução dos postos de trabalho no setor bancário em razão da maior utilização de máquinas e a conseqüente intensificação do trabalho nesse setor de atividade econômica.}

1 No ano 1994, a proporção entre o número de sentenciados em relação ao número de trabalhadores da Secretaria de Administração Penitenciária - SAP era de 217 sentenciados para cada 100 trabalhadores da SAP. Já em 2005, essa proporção foi de 468 sentenciados para cada 100 trabalhadores da $S A P$. seus códigos de ética profissional em referência à qualidade de atenção profissional oferecida.

Os agentes de segurança penitenciária (ASPs) e os agentes de escolta e vigilância penitenciária (AEVPs) são os grupos de trabalhadores que apresentam proporcionalmente a menor redução em seus quadros profissionais, pois estão envolvidos diretamente com as funções disciplinares. Entretanto, a sobrecarga de trabalho também se evidencia nesses grupos de trabalhadores, especialmente, entre os ASPs, pois o deslocamento de função para suprir carências do quadro de funcionários administrativos reduz o número geral de ASPs envolvidos nas atividades dos pavilhões prisionais.

Devemos destacar, ainda, o número excedente de sentenciados abrigados na instituição prisional como elemento que implementa a sobrecarga de trabalho ${ }^{1} \mathrm{e}$ contribui para o desvio de função profissional. Nas penitenciárias paulistas, o número excedente de sentenciados abrigados varia entre $20 \%$ e $40 \%$ de suas capacidades, totalizando um déficit superior a nove mil vagas (Secretaria da Administração Penitenciária, 2005).

\section{Histórico do trabalho:}

\section{ruptura da função social e sofrimento psíquico dos trabalhadores}

Ao investigarmos as relações entre subjetividade e trabalho, deparamo-nos com a dimensão histórica do trabalho. O que esses trabalhadores realizaram enquanto agentes do processo produtivo antes do ingresso nessa modalidade de trabalho? Tal apreciação é importante, pois, conforme indica Dejours (1992; 1999), o trabalhador suportará o sofrimento e o desgaste no trabalho em razão das vivências de prazer e ganhos secundários que obtiver. Delimitar o que é prazer ou sofrimento dependerá dos usos do corpo (Boltanski, 2004) no processo de socialização para o trabalho. Entre os entrevistados, encontramos trabalhadores que relataram um processo de ascensão social ao ingressarem no serviço público, deixando as atividades de trabalho agrícola num espaço transposto. Essa dimensão da mobilidade social (Althusser, 1999) é reforçada pelo processo seletivo exigido no ingresso ao trabalho na vigilância prisional, que é o avesso do desprendimento da força física no campo. Esse trabalhador rompeu as dimensões pejorativas atribuídas socialmente aos trabalhadores braçais ao assumir a função de agente repressor do Estado (Althusser, 1999), assim, pôde aspirar ao trabalho intelectualizado nas práticas administrativas da instituição prisional. A troca do trabalho no campo pela função de servidor público fornece uma valoração identitária para o sujeito.

Por outro lado, a dimensão histórica do trabalho pode ser indicativa de cisão de identidade profissional ou de esmorecimento das aspirações e projeções pessoais no espaço de sociabilidade do trabalho. Apresentaremos, a seguir, dois relatos de ruptura da identidade profissional no momento em que o trabalhador é inscrito na função de ASP. O primeiro relato apresenta, como pano de fundo, a reestruturação produtiva (Merlo, 2002), presente de modo intenso na década de 1990.

A reestruturação produtiva determinou a redução dos postos de trabalho no setor bancário em razão da maior utilização de máquinas e a conseqüente intensificação do trabalho nesse setor de atividade econômica. Após anos de trabalho em instituições 
financeiras estatais e privadas, um grande contingente de trabalhadores foi excluído dessas instituições em razão da reestruturação produtiva. Desse modo, trabalhadores egressos do setor bancário buscaram, no trabalho de vigilância prisional, a possibilidade de constituir as condições materiais para o sustento de suas famílias. Esses trabalhadores egressos do sistema financeiro vivenciam o cotidiano laboral nas penitenciárias como uma condição de intenso sofrimento ocasionado pela restrição das condições materiais de sobrevivência e a representação social (Joffe, 1995) valorada pejorativamente pela coletividade.

Lopes (2002) destaca que, no discurso social, é atribuída a esse trabalhador a execução de práticas de violência contra os sentenciados, práticas de corrupção e extorsão, além da responsabilização por fugas e motins. A autora ainda aponta a inexistência de relações desejantes como motoras dessa escolha profissional, pois, historicamente, os ASPs eram nomeados judicialmente para o cargo, e caso não assumissem o trabalho, sofreriam detenção. Essas são algumas dimensões da impregnação da identidade (Jodelet, 2005) dos ASPs com caracteres de valoração social pejorativa. Há ainda o receio dos trabalhadores em exporem sua identidade profissional e tornarem-se objeto de violência. Aos antigos agentes do sistema financeiro - e não é necessário destacar o incremento de valoração identitária desses trabalhadores na sociedade de capital -, resta a condição de restrição salarial, impregnação da identidade e exposição cotidiana à violência.

Outro grupo de trabalhadores merece destaque nessa condição de impregnação da identidade e intenso sofrimento psíquico no trabalho: os dekasseguis. A história de colonização do oeste paulista e do norte paranaense é composta pelo processo migratório de japoneses que buscavam possibilidades de trabalho na execução de atividades agrícolas. As famílias japonesas envolvidas nesse processo de colonização tornaram-se proprietárias de terras e obtiveram a concentração de renda e poder político a partir das atividades agrícolas.

Na década de 1980, a desestruturação da agropecuária no oeste paulista liberou um contingente de jovens e adultos que não encontravam outras colocações profissionais. O interesse do governo japonês em obter mão-de-obra para os postos de trabalho 3 $K s^{2}$ propiciou o engajamento de um grande número de descendentes de japoneses e seus cônjuges num processo migratório rumo ao Japão (Ocada, 2003).

De acordo com Galimberty (2002), há também uma dimensão subjetiva nesse processo migratório: ensaiam uma espécie de retorno as suas origens culturais, resgatam dimensões de valores, como a honra para suas famílias, visto que os japoneses que aqui chegaram não conseguiram retornar ao Japão. O embate entre as condições objetivas e subjetivas que determinam a migração e a realidade encontrada pelos dekasseguis dificulta a permanência no Japão por longos períodos. Retornar para a nação de origem (Brasil) é condição necessária para um grande contingente desses trabalhadores. Entretanto, há uma condição objetiva a se observar: se a partida rumo ao Japão ocorreu em razão das dificuldades de obter trabalho no Brasil, é necessário resolver esse entrave para o retorno. Assim, buscar o concurso público em qualquer função é a solução encontrada. As dificuldades inerentes à execução do trabalho 3Ks (Ocada, 2003), a fragmentação entre planejamento e execução da função produtiva e a impregnação com elementos pejorativos da identidade profissional, que eram condições
2 De acordo com Ocada (2003), os postos de trabalho 3 Ks são caracterizados por condições de trabalho constituidas por elementos pejorativos no Japão: kitanai (sujo), kiken (perigoso), kitsui (pesado). 
presentes no trabalho enquanto dekasseguis, continuam presentes nas atividades de ASP. Por essas condições expostas acima, a vivência de fracasso dos dekasseguis e, em conseqüência, o sofrimento psíquico, pode ser ampliada e cronificada.

Para outros trabalhadores que possuem instrução de nível superior, o trabalho nas unidades penitenciárias, apesar de propiciar alguma garantia financeira, é a realização de uma função profissional diferenciada do investimento libidinal vinculado à escolaridade do trabalhador. Essa circunstância pode intensificar as vivências de fracasso e inadequação à profissão que realizou sua formação. A situação acima também ocorre com estudantes universitários que buscam o trabalho nas unidades penitenciárias para reduzir o ônus familiar do seu curso superior. Esse sujeito vive a ruptura da vivência burguesa da compra dos serviços educacionais por seus tutores, deparando-se com o mundo do trabalho e suas experiências ansiogênicas, que são amplificadas pela experiência de violência e de risco à vida.

\section{As condições de trabalho}

Verificamos que os trabalhadores estão expostos a pelo menos três tipos de situações ansiogênicas, conforme proposta de Dejours (1992). A primeira refere-se ao risco iminente de violência inerente ao cotidiano do trabalho. Essa violência poderia inclusive se estender para além do local de trabalho, atingindo seus familiares. A possibilidade de o trabalhador e seus familiares vivenciarem situações de violência determina que permaneçam ligados a aparelhos da instituição prisional. As associações de funcionários de penitenciárias oferecem o acesso a um espaço de lazer, mas intensificam as condições de institucionalização dos trabalhadores. Nessas associações, a sensação de segurança oferecida pela presença dos agentes do trabalho encobre a restrição da circulação dos ASPs no espaço social: correr o risco de reconhecimento do trabalhador e de seus familiares pela rede relacional dos sentenciados nos espaços sociais é condição ansiogênica para os trabalhadores.

O tamanho reduzido das cidades do oeste paulista - populações inferiores a 30000 (trinta mil) habitantes - facilita o encontro entre esses elementos opostos da tessitura institucional. O relato de um dos entrevistados apresenta esta condição: "o que eu tenho mais medo neste trabalho é dos celulares (...) quando eu estou aqui dentro (penitenciária), quem cuida da minha família?" A possibilidade de ocorrência de violência contra os familiares dos ASPs determina a vigilância e a restrição da circulação social dos mesmos. Caso alguma situação de violência seja produzida contra sua família, a responsabilização do ASP é produzida pela perturbação do espaço fora do trabalho por caracteres constituintes da atividade profissional. A sensação de culpa em razão do possível sofrimento de um familiar violentado acompanha cotidianamente os trabalhadores.

O risco de violência é perpetuado por outras situações cotidianas do sistema prisional. Em alguns momentos, são encontradas cartas, em poder dos sentenciados, que contém listas com os nomes dos ASPs que devem ser executados em momentos de rebelião. Nesses momentos, os trabalhadores elencados nas listas de execução são remanejados para funções administrativas ou afastados do contato mais próximo com os detentos, assumindo postos de trabalho tais como os portões de acesso à muralha 
prisional. Entretanto, o medo relativo ao risco de morte no espaço fora do trabalho não é abarcado por essa medida administrativa. Essa condição ansiogênica é mobilizada, especialmente, por ações coletivas da organização hierárquica dos sentenciados. Quando os internos consideram pertinente pressionar a administração penitenciária, realizam reunióes coletivas nos raios prisionais. Nessas ocasióes, os sentenciados costumam rezar conjuntamente e em voz alta. Tal prática propicia a comunicação entre os raios prisionais e dispara nos ASPs o medo de ocorrência de uma rebelião e, em conseqüência, a execução da lista de condenados à morte, pois, se os sentenciados solicitam a proteção da divindade, alguma violência pode ser produzida.

A segunda situação ansiogênica refere-se à percepção, pelo trabalhador, da degradação de sua saúde. A degradação produzida pela ação das cargas de trabalho (Laurrel; Noriega, 1985) abrange desde cargas biológicas até as cargas psíquicas de trabalho. As refeições produzidas pelos sentenciados são possíveis fontes de contágio por hepatite. Os ASPs entrevistados relataram uma possível prática, entre os sentenciados que trabalham na cozinha, de cuspir na alimentação produzida.

Há também o risco de contágio por sarna e tuberculose no ambiente prisional. As condições precárias de abrigo dos sentenciados tornam comum a ocorrência dessas doenças e ganham uma nomeação pejorativa no discurso dos entrevistados: zica de cadeia. Além da condição biológica de estar afetado por essas doenças, há uma perturbação dos caracteres de identidade dos trabalhadores. Portar doenças comuns entre os sentenciados é uma situação de partilha das dimensões de vida dos sentenciados.
A impregnação de identidade proposta por Jodelet (2005) se materializa, assim, no corpo dos trabalhadores. Subjetivamente, essa aproximação é muito perigosa; faz com que os ASPs vivenciem dimensões que negam e em que empregam suas potencialidades para corrigir e disciplinar. São, ainda, agentes epidemiológicos de transmissão dessas doenças, especialmente a seus familiares. Nessa última situação, encontramos grande preocupação dos trabalhadores nos momentos que envolvem o controle de episódios violentos e apoio aos serviços de saúde. A possibilidade de contágio com o vírus HIV se vincula cotidianamente ao menos a essas duas situações. Existe também a possibilidade de contágio em momentos de rebelião em que os ASPs são tomados como reféns.

As situações de exposição a cargas biológicas apresentadas acima são também vivenciadas como cargas psíquicas do trabalho. Por isso, a hipertensão (Maciel, 1994) e a doença dos nervos (Jacques, 2002) são manifestações da degradação da saúde desse grupo de trabalhadores. Nessas duas manifestações, o contato com os sentenciados e suas implicações determina sofrimento psíquico no trabalho. A atividade cotidiana de abertura das celas para o banho de sol e seu posterior fechamento para a reclusão é um momento de grande risco para os ASPs: os trabalhadores adentram os raios prisionais e possibilitam a circulação de centenas de detentos. Isso acontece diariamente.

Quando ocorrem revistas nas celas à procura de armas, celulares e drogas - operação denominada blitz -, há a possibilidade direta da ocorrência de violência. Esse trabalhador se inscreve nas posições de ator e sujeito dos episódios de violência: ator, ao executar práticas disciplinares, e sujeito, ao sofrer a violência. Enquanto executor de violência, 
é marcado pelos sentenciados como aquele que deve ser hostilizado. Como vítima da violência, há a fragilização de seu discurso disciplinar sobre a população carcerária e, como conseqüência, sofre escárnio, inclusive dos ASPs. Assim, podemos caracterizar a dinâmica grupal dos ASPs como xenofóbica.

De acordo com Dante Moreira Leite (2002), o grupo xenofóbico apresenta um discurso ideológico rígido e hostiliza os sujeitos que não partilham de seus ditames ou os que encontram dificuldades em reproduzi-lo. Por isso, é muito importante, para os trabalhadores que foram vítimas de violência em momentos de rebelião, participar, imediatamente após sua libertação, das sanções disciplinares contra prisioneiros. Não executar as práticas punitivas previstas no discurso ideológico do grupo xenofóbico inscreve o trabalhador numa posição de zombaria; um sujeito comédia, de acordo com o discurso do grupamento profissional.

O risco de indisposição entre sentenciados e trabalhadores ocorre também em pequenas práticas cotidianas, onde o ASP é solicitado a conseguir medicamentos, atendimento pela equipe interdisciplinar, inclusão de novos nomes em seu rol de visitantes ou informações sobre a progressão da sentença. Mesmo não fazendo parte do trabalho prescrito (Dejours, 1994), os trabalhadores podem executar essas funções como forma de estabelecer empatia junto aos detentos e obter ganhos secundários nessa relação, tal como proteção física, caso venha a se tornar refém numa rebelião. Vale considerar que a organização de ganhos secundários, como foi proposta acima, pode produzir situações conflituosas caso o ASP se comprometa com as solicitações e esbarre em entraves institucionais para realizá-las.
A terceira situação ansiogênica refere-se à escolha dessa profissão: a escolha profissional se processa em razão da necessidade da obtenção de sustento e não considera o desejo do sujeito na escolha profissional. Assim, esse trabalho se estrutura a partir da disciplina da fome, conforme a proposta de Dejours (1992). Essa forma de se articular com a atividade produtiva pode não apresentar ressonância simbólica para o trabalhador e ofertar constantemente desprazer. Assim, esse trabalho se constitui em fonte de sofrimento psíquico.

\section{Considerações finais}

As dimensões de sofrimento psíquico enfrentado pelos ASPs podem ser representadas pela nomeação construída pelo discurso subjetivo do trabalho (Dejours, 2001) para o sistema prisional. Essa nomeação é caracterizada por sua expressão conflituosa no discurso dos trabalhadores: sucursal do inferno, condomínio do diabo, cemitério dos vivos (Vasconcelos, 2000). Não bastasse trabalhar num local tão turbulento e amedrontador, os trabalhadores ainda devem executar as funções de controle à violência e manter a disciplina dos corpos.

O controle dos sentenciados é obtido por meio de práticas repressivas, com conseqüências e reações imprevisíveis, onde ninguém tem o efetivo domínio das situações. A substituição da avaliação da equipe interdisciplinar, como meio de determinar a progressão do sentenciado no sistema prisional pelo relato da conduta cotidiana dos apenados captados pelos ASPs, foi imaginada para potencializar as ações disciplinares desses trabalhadores. Entretanto, essa condição implicou um aumento nas condições de embate entre ASPs e sentenciados. A sugestão dos sentenciados da existência de listas de ASPs 
que devem ser mortos em momentos de rebelião pode ter seus números aumentados pela utilização desse modelo disciplinar de avaliação.

O embate entre sentenciados e ASPS também é fonte de sofrimento para os trabalhadores quando ocorre alguma violência. As sindicâncias realizadas contra os trabalhadores continuam existindo no histórico profissional do trabalhador mesmo quando ele não é condenado. A submissão dos trabalhadores aos processos de sindicância provoca sensações de desvinculação do discurso institucional. O distanciamento do trabalhador da prática discursiva da instituição pode posicioná-lo numa dinâmica de identificação com os sentenciados. Em caso de condenação em uma sindicância, o trabalhador pode ser exonerado e até levado à prisão. A exoneração impediria a participação do trabalhador em qualquer outro emprego público e levaria à condenação à prisão e à exposição à violência dos sentenciados.

Algumas situações relacionadas à organização do trabalho refletem a precariedade das relações de mobilização da mão-de-obra: composição do salário mensal por proporção significativa de gratificações, restrição no pagamento dessas gratificações em caso de acidente do trabalho e doença profissional, insuficiência e irregularidade no pagamento de auxílio transporte ${ }^{3}$, cerceamento de informações sobre o acesso aos planos de ascensão profissional (plano de carreira), inexistência de políticas institucionais que possibilitem o acesso dos ASPs ao ensino superior, insuficiência da cobertura oferecida pelo plano de saúde destinado aos ASPs, restrição na oferta de serviços em Psicologia pela cobertura securitária de saúde profissional, funcionamento moroso das práticas institucionais que permitem a permuta de trabalhadores entre as unidades penitenciárias estaduais e intensificação do ritmo de trabalho em razão do quadro de funcionários reduzido, e o abrigo de sentenciados acima da possibilidade de lotação das penitenciárias. As vivências de ansiedade relacionadas à execução do trabalho, a contaminação do espaço fora do trabalho pelo risco de violência pessoal e de seus familiares, a impregnação da identidade dos trabalhadores por aspectos pejorativos vinculados à violência e à ocorrência de afecções psicossomáticas, como a hipertensão arterial, determinam a degradação do quadro geral de saúde dos trabalhadores. As características psicogênicas das cargas de trabalho (Laurrel; Noriega, 1985) a que estão expostos os ASPs podem determinar maior ocorrência de sofrimento psíquico nesse grupo de trabalhadores quando comparados com a população em geral.

Em virtude dessas situações, propusemos à administração penitenciária a organização de um serviço de saúde mental exclusivo para esses trabalhadores. Esse serviço, que funciona desde o mês de agosto de 2005, é realizado por alunos de graduação em Psicologia em estágio supervisionado profissionalizante. Tal espaço foi oferecido para acolher o sofrimento oriundo das práticas profissionais. Foi constituído em modelo de plantões diários de graduandos em Psicologia a fim de oferecer a devolutiva sobre a caracterização das condições de trabalho ao maior número possível de trabalhadores. O contato com o trabalho reconstituído coletivamente pelo discurso dos trabalhadores (Ferreira et al., 1997) e situado numa dimensão sociohistórica pela ação interpretativa da prática em Psicologia permitiu a mobilização subjetiva dos trabalhadores em torno de dimensões institucionais que aumentavam as condições de desgaste no trabalho, tais como a rigidez
3 Deve-se destacar que as penitenciárias são construidas em locais distanciados dos conglomerados urbanos municipais, nas proximidades de rodovias que servem os Municípios do oeste paulista. 
da hierarquia institucional e o cerceamento dos espaços de progressão profissional.

O contato entre os trabalhadores e o serviço de Psicologia evoluiu da mobilização dos conteúdos diretamente relacionados às práticas institucionais para as dinâmicas de organização afetiva dos sujeitos e de suas famílias. Nessa ordenação do espaço de acolhimento ao sofrimento psíquico, a confluência entre subjetividade, família e trabalho foi organizada de modo particularizado por cada ASP. Aos trabalhadores que realizaram a escolha de situar seus afetos cindidos no espaço de acolhimento ao sofrimento psíquico, houve a realização de encontros semanais com um discente específico de Psicologia, nos quais era preconizada a manutenção do vínculo terapêutico. Assim, o serviço em saúde mental organizado na instituição prisional se caracterizou por oferecer formas diversificadas de acolhimento ao sofrimento psíquico, tais como uma prática emergencial em saúde mental e um espaço individualizado de mobilização subjetiva para o enfrentamento das práticas disciplinares institucionais.
Oferecendo progressão a essas práticas de atenção à saúde, pretendemos estender esse modelo de atenção à saúde mental de trabalhadores a outras penitenciárias do oeste do Estado de São Paulo. Atualmente, concentramos nossas ações na produção de saberes sobre psicopatologia do trabalho, conforme as indicações de Codo (2004). Nessa proposta de seqüência do trabalho, o discurso dos trabalhadores indicou a negação do risco no trabalho e a fragmentação das defesas coletivas dos trabalhadores, em razão de interesses particulares por postos administrativos e do aumento de poder dos sentenciados. Apresentaram também vivências paranóides relacionadas aos riscos no trabalho e ao temor que familiares pudessem ser vitimados. A participação de mulheres na execução de revistas propicia a constituição de um conflito ideológico entre o relato de sofrimento dos familiares dos sentenciados e o ostensivo controle institucional. A tomada de trabalhadores como reféns, em rebeliões, os aproxima do risco de morte. Nessas ocasiões, alguns trabalhadores aguardavam se deparar com os sentenciados disciplinados nas celas, e outros apresentavam um estado póstraumático de aversão ao trabalho. 
Cassiano Ricardo Rumin

Psicólogo (FFCL/UNESP) - CRP 06/63046 - Especialista em Saúde Pública (FCF/UNESP) - Mestre em Ciências Médicas (FMRP/USP) - Docente das Faculdades Adamantinenses Integradas (FAI) e da União das Faculdades Dracenenses (UNIFADRA). Avenida Stélio Machado Loureiro, n.428. Jardim Marajá. Pacaembu (SP) CEP: 17860000 Tel.: (18) 38621458

E-mail:casrumin@usp.brou cassianorumin@hotmail.com

ALTHUSSER, L. Sobre a Reprodução. Petrópolis: Vozes, 1999.

BOLTANSKI, L. As Classes Sociais e o Corpo. São Paulo: Paz e Terra, 2004.

CAMARGO, A. M. M. P.; ANEFALOS, L. C.; CASER, D. V.; COELHO, P. J.; OLIVETTI, M. P. A. Alteração na Composição da Agropecuária no Estado de São Paulo, 1983-93. Informações Econômicas, São Paulo, v.25, n.5, pp. 49-81, 1995.

CODO, W. O Trabalho Enlouquece? Um Encontro entre a Clínica e o Trabalho. Petrópolis: Vozes, 2004.

DEJOURS, C. A Loucura do Trabalho: Estudo de Psicopatologia do Trabalho. São Paulo: Cortez/Oboré, 1992.

Psicodinâmica do Trabalho: Contribuições da Escola Dejouriana à Análise da Relação Prazer, Sofrimento e Trabalho. São Paulo: Atlas, 1994.

Identidade, Reconhecimento e Transgressão no Trabalho. São Paulo: Fundap/EAESP/FGV, 1999. FGV, 2001.

A Banalização da Injustiça Social. Rio de Janeiro:

FERREIRA, L. L.; GONZAGA, M. C.; DONATELLI, S.; BUSSACOS, M. A. Análise Coletiva do Trabalho dos Cortadores de Cana da Região de Araraquara, São Paulo. São Paulo: FUNDACENTRO, 1997.

GALIMBERTTI, P. O Caminho que o Dekassegui Sonhou (Dekassegui No Yumê-ji): Cultura e Subjetividade no Movimento Dekassegui? São Paulo: EDUC/FAPESP; Londrina: Ed. UEL, 2002

JACQUES, M. G. "Doença dos Nervos": uma Expressão da Relação entre Saúde/Doença Mental. In: Jacques, M. G.; Codo, W. (org.) Saúde Mental \& Trabalho: Leituras. Petrópolis: Vozes, 2002, pp. 98-111.
JODELET, D. Loucuras e Representações Sociais. Petrópolis: Vozes, 2005.

JOFFE, H. Textos em Representações Sociais. Petrópolis: Vozes, 1995.

LAURREL, A. C.; NORIEGA, M. Processo de Produção e Saúde: Trabalho e Desgaste Operário. São Paulo: Hucitec, 1985.

LEITE, D. M. O Caráter Nacional Brasileiro. São Paulo: Fundação Editora da UNESP, 2002

LOPES, R. O Cotidiano da Violência: o Trabalho do Agente de Segurança Penitenciária nas Instituições Prisionais. Psicologia para a América Latina, México, v.1, n. 0, pp.15-22, 2002.

MACIEL, C. L. C. Emoção, Doença e Cultura: o Caso da Hipertensão Essencial. In: Romano, W. B. (org.). A Prática da Psicologia nos Hospitais. São Paulo: Pioneira, 1994.

MERLO, A. R. C. Reestruturação Produtiva no Setor Bancário Brasileiro e Sofrimento dos Caixas Executivos: um Estudo de Caso. Psicologia \& Sociedade, Porto Alegre, v.14, n.1, pp. 103-122, 2002.

OCADA, F. K. Trabalho, Sofrimento e Migração Internacional: o Caso dos Brasileiros no Japão. Idéias, Campinas, v.9, n.10, pp. 175-217, 2003.

SECRETARIA DE ADMINISTRAÇÃO PENITENCIÁRIA. História da SAP. Disponível em: www.sap.sp.gov.br Acesso em 02/03/2005.

SILVA, M. A. M. Errantes do Fim do Século. São Paulo: Fundação Editora da UNESP, 1999

A Luta pela Terra: Experiência e Memória. São Paulo: Fundação Editora da UNESP, 2004.

VASCONCELOS, A. S. F. A Saúde sob Custódia: um Estudo sobre Agentes de Segurança Penitenciária no Rio de Janeiro. Dissertação de Mestrado. Fundação Oswaldo Cruz, Escola Nacional de Saúde Pública, 2000, 66 p. 